Ministerstwo Nauki

i Szkolnictwa Wyższego

Digitalizacja archiwalnych numerów czasopisma naukowego Analecta Cracoviensia 1-24 (1969-1992) i ich publikacja w otwartym dostępie - zadanie finansowane w ramach umowy 672/P-DUN/2017 ze środków Ministra Nauki i Szkolnictwa Wyższego przeznaczonych na działalność upowszechniającą naukę

\title{
CUDA JASNOGŌRSKIE SPISANE W ROKU 1435
}

Król Władysław Jagiełło w liście z r. 1429 do papieża Marcina V, popierając starania paulinów o odpusty dla kościoła na Jasnej Górze, wspomina o wielu cudach, które się tam dzieją ${ }^{1}$. Również Jan Długosz, fundator klasztoru paulińskiego na Skałce, opisując w swojej Historii pod r. 1430 napad łotrzyków na klasztor w Częstochowie, mówi o pątnikach z całego Królestwa, Sląska, Prus i Węgier, którzy wędrowali tam dla cudów, doznawanych za przyczyną Matki Boskiej 2.

Spisy cudów (miracula) stanowią cenne źródła do badań nad rozwojem kultu oraz ruchem pątniczym w danym miejscu odpustowym. Również cuda jasnogórskie były przedmiotem studiów ${ }^{3}$. Ostatnio na jubileusz 600-lecia bardzo szczegółowego ich opracowania podjęła się s. Aleksandra Witkowska 4 . Dotąd do dyspozycji badaczy pozostawały tylko szesnastowieczne przekazy. Za najstarszy ich zbiór uchodził spis dołączony do Historia pulchra et etupendis miraculis reserta imaginis Mariae quomodo et unde in Clarum Montem Czastochoviae et Olsztyn advenerit, opracawanej przez paulina Piotra Rydzyńskiego (Risiniusa), wydanej w Krakowie w r. 1524. W przedmowie wspomniany został stary, zniszczony kodeks, który służył mu za podstawę. Jan Pirożyński datuje powstanie tego nieistniejącego obecnie rękopisu na ostatnie ćwierćwiecze XV w., przyjmu-

${ }^{1}$ Cf. J. Fijałek, Zbiór dokumentów zakonu OO. Paulinów $w$ Polsce, z. 1, Kraków 1938, s. 175 (nr 95): [ - ] quia in dicta ecclesia multorum miraculorum sepe clarent virtute Dei misteria.

2 Cf. Ioannis Dlugossii Historiae Polonicae libri XII, t. 4, Cracoviae 1877, s. 399-400: [ - - ] eo quod illic ex universo Regno Poloniae et partibus vicinis Slesia videlicet, Moravia, Prussia, Hungaria in festivitatibus Sanctae Mariae, cuius in loco illo rara et devota sculpturae habebatur imago, fiebat concursus propter stupenda prodigia, quae in curatione languidorum per suffragium Dominae nostrae in loco illo contingebant.

${ }^{3}$ Por. K. Pieradzka, Fundacja klasztoru jasnogórskiego $w$ Częstochowie $w 1382$ r., Kraków 1939; S. S z a fra n i e c, Jasna Góra. Studium z dziejów kultu Matki Boskiej Częstochowskiej, „Sacrum Poloniae Millenium” 4 (1957) s. 32-37; K. S zafraniec, Z dziejów Jasnej Góry, Warszawa 1980, s. 149.

4 A. Witkowska, Najstarsze źódła do dziejów jasnogórskiego kultu pątniczego, „Studia Claromontana” 1 (1981) s. 58-76. 
jąc że cuda zaczerpnął Rydzyński z prowadzonych w klasztorze libri miraculorum ${ }^{5}$. Cuda te są $\mathrm{w}$ większości niedatowane. Jeżeli chodzi o wiek $\mathrm{XV}$, to tylko przy uzdrowieniu z trądu księdza Mikołaja z Sochaczewa wpisano r. 1402 . S. Witkowskiej udało się ponadto ustalić, że Risiniusz uwzględnił trzy datowane cuda piętnastowieczne z roku 1432 i 1434 .

W r. 1568 zostało wydane w Krakowie tłumaczenie dziełka Risiniusza dokonane prawdopodobnie przez Mikołaja z Wilkowiecka, również paulina, pt. Historya o obrazie $w$ Częstochowie Panny Maryey y o Cudach rozmaitych tey Wielebney Tablice. Ten spis cudów zawiera jednak wskazane przez s. Witkowską różnice, pozwalające wyciągnąć wniosek, że wyboru dokonano niezależnie od Historia pulchra. Natomiast najstarszy rękopiśmienny Liber miraculorum pochodzi dopiero z r. $1591^{6}$.

W czasie prac w Oddziale Rękopisów Biblioteki Jagiellońskiej natrafiłam na spis cudów jasnogórskich na karcie ochronnej rękopisu BJ 2322. Jest to urzędowy rejestr uzdrowionych pątników za przyczyną Matki Boskiej Częstochowskiej, spisany w r. 1435, tj. w pięćdziesiąt lat po założeniu klasztoru jasnogórskiego przez Władysława Opolczyka. Rękopis napisany został około r. 1470 i zawiera ekscerpty o spowiedzi i o grzechach z Pantheologii, sumy teologicznej Rainera z Pizy, dominikanina zmarłego w r. 1351. Są one poprzedzielane kopiami kazań Mikołaja z Kościana, profesora dekretów Uniwersytetu Krakowskiego; oficjała i wikariusza generalnego poznańskiego ?, oraz innymi drobnymi tekstami. Powstała w ten sposób swego rodzaju „Summa de poenitentia” ${ }^{8}$. Kodeks

5 J. Pirożyński, Najstarszy zachowany drukowany przekaz legendy o obrazie Matki Boskiej Częstochowskiej, „Biuletyn Biblioteki Jagiellońskiej” 23 (1973) s. 152.

- Archiwum OO. Paulinów na Jasnej Górze, rkp. 2096: Miraculorum B. V. Monasterii Częstochoviensis tomus primus. - Por.: J. $\mathrm{Z}$ b u dniew e k, Kopiarze zakonu Paulinów $w$ Polsce do końca XVII wieku, „Archiwa, Biblioteki i Muzea Kościelne w Polsce" 34 (1977) s. 296.

7 Mikołaj Hesken z Kościana, magister artium Uniwersytetu Krakowskiego (1439), doktor dekretów, kanonik poznański (1454), oficjał i wikariusz generalny poznański. Zmarł w r. 1485; zob. Polski Słownik Biograficzny, t. 21, s. 116-117.

${ }^{8}$ O treści kodeksu BJ 2322 (datowanego na podstawie filigranów) informuje zapiska na jego karcie ochronnej (f. IIv): Contenta in hoc libro sunt ista: In primis ponitur Quadriga virtutum [f. $1 \mathrm{r}-9 \mathrm{r}$ ]. Item diverse auctoritates diversorum sanctorum doctorum de conflictu viciorum et virtutum [f. $9 \mathrm{v}-19 \mathrm{v}$ ]. Item tractatus de septem peccatis mortalibus et de aliis peccatis interpositis. Excerptus de Pantheologia [f. $19 \mathrm{v}-174 \mathrm{v}$ ]. Item de multiplici genere ypocritarum [f. $174 \mathrm{v}-176 \mathrm{r}$ ] Item de VII viciis quomodo intelliguntur per quedam animalia. Notabile Roberti Holgot [f. $176 \mathrm{r}-\mathrm{v}, 175 \mathrm{v}$ ]. Item de detractione, devotione, presumptione et suspitione. Ex Pantheologia [f. $177 \mathrm{r}-187 \mathrm{r}$ ]. Item sermo de sancta Cruce super themate: $\mathrm{Si}$ quis vult venire post me [f. $187 \mathrm{v}-190 \mathrm{v}]$. Item notabile de modo perveniendi ad graciam Dei [f. 191r-192r]. Item de consensu. Item de dilectione. Per longum ex Pantheologia [f. 192r-222v]. Item notabilia de multiplici cruce super verbis: $\mathrm{Si}$ quis vult venire etc. [f. $223 \mathrm{r}-228 \mathrm{v}$ ]. Item de dormitione, consolatione et gaudia multiplici super epistolas prime, secunde et tercie dominice Adventus. Ex dictis magistri Nicolai de Costen [f. 229r-238v]. Item de iudicio multiplici, de ignorantia, de mendatione, de ira, de furto, de iuramento, de multiplici genere homicidiorum, de odio et de ebrietate. Collecta ex dictis predicti magistri Nicolai de Costen dicti 
nie posiada żadnych zapisek własnościowych. Nie wiadomo też, kto i kiedy go przepisał oraz dla kogo. Karta ochronna wskazuje, że rękopis powstał prawdopodobnie w środowisku paulińskim, zwłaszcza że na odwrocie małej, dodanej (również makulaturowej) karteczki, związanej z tekstem rękopisu, znajduje się prośba o modlitwę w intencji jakiegoś zakonnika 9 .

Interesujący nas dokument napisany został drobnym pismem, przez nie znanego z imienia notariusza. Niestety dokument ten został znacznie obcięty przez introligatora: lewy $\mathrm{i}$ dolny margines wraz $\mathrm{z}$ tekstem oraz prawy nie zapisany. Powstała w ten sposób karta pergaminowa o wymiarach $23,5 \times 20,5 \mathrm{~cm}$, użyta następnie na postfolium przy oprawie wspomnianego już kodeksu. Omawiany fragment obejmuje 46 wierszy. Na odwrociu pergamin pozostał nie zapisany. W tekście cudów znajdujemy kilka pomyłek pisarskich, co by sugerowało, że dokument zaraz po ponownym, bezbłędnym już skopiowaniu, został - jak to często się zdarzało - skazany na makulaturę. Jednak użycie go do oprawy ok. r. 1470, tj. kiedy powstał rękopis, świadczy raczej, że makulaturą stał się on dopiero około tego roku, zapewne w związku z przeredagowywaniem, czyli nowym opracowywaniem cudów, może nawet do wspomnianej powyżej Historii. Przez przycięcie dokument utracił wiele ważnych elementów, a zachowany tekst został bardzo okaleczony. Brakuje w nim, jeżeli nie całych zdań, to na pewno dużych ich fragmentów oraz zakończenia, trudnych do uzupełnienia. Naturalnie nie wiadomo jak długi był sam dokument, ani zawarty w nim spis cudów.

Dokument ten został wystawiony w r. 1435 w Częstochowie, co wynika $\mathrm{z}$ tekstu. Wprawdzie przez przycięcie pozostała $\mathrm{z}$ datacji rocznej tylko końcowa cyfra ,quinto”, ale z łatwością można ją uzupełnić, gdyż rzecz miała miejsce za pontyfikatu Eugeniusza IV (1431-1439). Przed nie znanym z imienia notariuszem stawił się osobiście Andrzej, przeor prowincjonalny paulinów z diecezji krakowskiej (,,prior provincialis fratrum heremitarum sancti Pauli, primi heremite, ordinis sub regula b. Augustini diocesis Cracoviensis") razem ze swoimi współbraćmi zakonnymi. W wigilię Zielonych Świątek oraz w trzy dni świąteczne następujące po niej, tj. 4-7 czerwca, przyjmował relacje o cudach. Pytał (requisivit) o choroby i różne uciski, z których zostali uleczeni bądź uwolnieni — jak podawali pod przysięgą do publicznej wiadomości - przybyli w tych dniach ,ad limina beate Marie semper Virginis illibate” pielg-

Heszkyen decretorum doctoris, canonici Poznaniensis super epistolas [f. $239 \mathrm{r}-262 \mathrm{v}$ ]. Item tractatus de penitentia et eius partibus diffusus. Ex Pantheologia collectus [f. $263 \mathrm{r}-431 \mathrm{r}$ ]. Item notabilia de mortalis peccati malicia [f. $431 \mathrm{v}-498 \mathrm{v}$ ]. Warto jeszcze dodać, że podobne pismo ma ręlkopis BJ 2303 z r. 1468/9 (np. f. 158v).

9 „Honorabilis domine, quidam adolescens intravit religionem, petit propter Deum a populo unum Ave Maria, ut Deus confirmat ipsum in proposito" (rkps BJ 2322, f. 240v). 
rzymi. Notariusz wyraził przekonanie w sumieniu, że zeznania ich były prawdziwe. Występował jeszcze drugi notariusz; była to więc komisja powołana do spisania i zbadania wydarzeń podawanych za cudowne.

Przeor Andrzej znany jest $\mathrm{z}$ dokumentu biskupa krakowskiego Zbigniewa Oleśnickiego. W r. 1436 na prośbę przeora Andrzeja Oleśnicki transumował i zatwierdził przez swojego sekretarza Jana Długosza dwa przywileje nadawcze Jagiełły dla paulinów częstochowskich ${ }^{10}$. Zielone Świątki i sześć dni po nich następujące były na Jasnej Górze dniami odpustowymi. Papież Marcin V udzielił bowiem specjalnych odpustów (p)d warunkiem spowiedzi i złożenia jałmużny na budującą się świątynię) pątnikom odwiedzającym kościół w święta Pańskie, a więc i w Zielone Świątki, w uroczystości Matki Boskiej (Narodzenie, Zwiastowanie, Oczyszczenie i Wniebowzięcie), w Narodzenie św. Jana, w dzień Wszystkich Swiętych oraz w oktawy tych świąt, a ponadto w sześć dni po Zesłaniu Ducha św. ${ }^{11}$

Zachowany fragment dokumentu notarialnego obejmuje około pięćdziesiąt zapisek o cudach. Nie można policzyć ich dokładnie, gdyż w skutek obcięcia nie zawsze wiadomo, gdzie się kończyły. Z niektórych znamy tylko osobę, $\mathrm{z}$ innych dolegliwość, na którą cierpiała. Nie można też domyślić się, ilu było uzdrowionych. Kilkanaście zapisek z tego dokumentu można odnaleźć, choć $\mathrm{w}$ innej redakcji i z przekręceniami w nazwach osobowych i miejscowych, w spisie cudów zamieszczonym przez Rydzyńskiego, a kilka w tłumaczeniu Mikołaja z Wilkowiecka, z czego wynika, że korzystali oni z dawniejszych spisów.

Te urzędowe zapisy uzdrowionych $\mathrm{i}$ wybawionych $\mathrm{z}$ różnych opresji za przyczyną Matki Boskiej Częstochowskiej są raczej krótkie, nierozwinięte stylistycznie i tym różnią się od późniejszych. Zawierają przede wszystkim imię i miejscowość, z której pochodził pątnik, oraz na co cierpiał, względnie jaki spotkał go nieszczęśliwy wypadek. Wyjątkowo dodane jest, że wyzdrowiał (,sana facta est ad preces beate Marie virginis"). W innych wypadkach należy się takiej uwagi domyślać, choć nie została ona zapisana.

Uzdrowieni zgłaszali się przed komisją zasadniczo osobiście. W jednym wypadku wystąpiła żona w imieniu męża. O dzieciach relację składali rodzice. Wśród uzdrowionych występuje więcej mężczyzn (ok. 30) niż kobiet (ok. 20), ale bywały też dzieci. Nie zidentyfikowałam żadnych znanych ani wybitniejszych osób, co wskazywałoby na ludowość kultu w tym okresie. Mniej więcej połowa osób wymienionych w spisie pisała się z miasta, a połowa ze wsi. Nie wspomniano przy żadnej osobie, aby była pochodzenia szlacheckiego.

10 Fi jałek, jw., s. 205 (nr 109).

$11 \mathrm{Fi} \mathrm{jałek,} \mathrm{jw.} \mathrm{s.} \mathrm{175-176} \mathrm{(} \mathrm{nr} 96$ ). 
Bardzo ciekawa jest topografia miejscowości, z których pochodzili ci pątnicy jasnogórscy. Niestety nie zawsze można je z całą pewnością zlokalizować, gdyż nazwy miejscowe się powtarzają, względnie zapis sporządzony na podstawie ustnej relacji nie zawsze pozwala na identyfikację. Niemniej można twierdzić, że większość pielgrzymów pochodziła ze Sląska, a nawet dokładniej - z Opolszczyzny. Są to następujące miejscowości: Koźle, Krapkowice, Racibórz, Opawa, niestety niezlokalizowane Larysławice koło Rybnika, Szonowice, Namysłów, Głogów, a prawdopodobnie również Domaradz, Warta (Bardo), Żory i Krzyżowniki, które to nazwy występują także gdzieindziej. Poza tym pielgrzymi przybyli także z Małopolski: Pilzno, Olkusz, Kruplin, Wietrzychowice, Sułkowice, Kraków. Nie ma pątników z okolic Częstochowy, z wyjątkiem wymienionego już miasteczka Kruplin, z którego dziesięcinę zapisał paulinom $\mathrm{w}$ dokumencie fundacyjnym Władysław Opolczyk ${ }^{12}$. W większości wypadków z poszczególnych miejscowości występuje jeden uzdrowiony. Zwraca uwagę Pilzno, z którego pisały się aż cztery osoby. Po dwie zaś pochodziły z Raciborza (nadto jedna $\mathrm{z}$ ziemi raciborskiej), Domaradza i Wolbromia.

Choroby, z których - jak wyznali pielgrzymi - zostali cudownie uzdrowieni $\mathrm{w}$ wielu wypadkach określone zostały bardzo ogólnie, a więc: ciężka choroba, ból całego ciała, chore nogi, ręce, niemożność chodzenia, mówienia, jedzenia czy picia. W niektórych wypadkach dokładniej podano ową dolegliwość: febra, wrzody, puchlina, głuchota, choroba oczu etc. W jednym tylko przypadku zapisano, że zmarły ożył. Do ucisków (oppressiones) zaliczyć trzeba to, co ucierpieli od husytów (uwięzienie, powieszenie, straty materialne). Przy tej okazji zapisane zostało nazwisko husyty Puklicza. Należy przypomnieć, że był to okres nasilonych walk husyckich, zwłaszcza na Śląsku.

W dokumencie opisano kilka nieszczęśliwych wypadków: poparzenie dziecka, utonięcie w Odrze, przeszycie strzałami itp. W niektórych zapisach znajdują się dodatkowe szczegóły, np. długość trwania choroby, towarzyszący jej wielki ból, podkreślenie że nikt nie wierzył w wyzdrowienie chorego. Pątnicy zeznawali, że byli w agonii i trzymali już gromnicę w rękach. Notariusz raz zaświadczył, że miał w swoich rękach coś, co świadczyło o cudownym wyleczeniu. Na podstawie Rydzyńskiego można się domyślać, że chodziło o kamień nerkowy.

Nie wiadomo, z jakiego okresu pochodzą te cudowne uzdrowienia. Zaznaczyć może trzeba, że w spisie nie występuje wspomniany już cud z r. 1402, najstarszy znany. Nie mogą wszystkie te zapiski dotyczyć cudów,

12 Por.: S., S. M. Z Z jączkowscy, Materiaty do słownika geograficzno-historycznego dawnych ziem lęczyckiej i sieradzkiej do r. 1400, cz. 1, Łódź 1966, s. 149. 
które zdarzyły się w jednym, tj. 1435 roku. Niewątpliwie ich spisanie należy łączyć z zabiegami paulinów, dążących do ożywienia kultu, czemu miały służyć również uzyskane od papieża i biskupa krakowskiego odpusty. Cuda zaś popularyzowały miejsce pielgrzymkowe, a ich opisy jeszcze bardziej rozsławiały to miejsce.

Gdy po wypadkach z r. 1430 cudowny obraz częstochowskiej Madonny odnowiony w Krakowie znalazł się z powrotem na Jasnej Górze, zapewne zostały zorganizowane specjalne uroczystości z tej okazji, a może także ogłoszono termin spisywania cudów i łask. Rezultatem tego byłby omawiany dokument z r. 1435, zawierający zasadniczo sumaryczny spis wcześniejszych cudów. Fakt ten można by też łączyć w jakiś sposób z powstaniem konfraterni jasnogórskiej, poświadczonej dopiero dla późniejszego okresu.

Uszkodzony dokument nie pozwala na wyciągnięcie zbyt daleko idących wniosków. Niemniej świadczy on niezbicie, że w r. 1435 obraz Madonny na Jasnej Górze cieszył się powszechnym, wcale nie lokalnym kultem. Przewaga zapisanych w nim Ślązaków potwierdza świadectwo Jana Długosza, zamieszczone w jego Historii. Narzuca się wniosek, że związki Częstochowy z Opolszczyzną należy przypisać nie tylko bliskie$\mathrm{mu}$ sąsiedztwu, lecz także wiązać z Władysławem Opolczykiem, fundatorem paulinów na Jasnej Górze i prawdopodobnie propagatorem kultu cudownego obrazu.

Dokument z r. 1435 jest ważnym źródłem do historii kultu Matki Boskiej Częstochowskiej w jego najwcześniejszym okresie. Dzięki temu spisowi będzie można - z ogólnej liczby 289 cudów obliczonych dla wieku XV i XVI - wydzielić te, które miały miejsce przed r. 1435, a także dodać nie znane, pominięte przy redagowaniu szesnastowiecznych list ${ }^{\mathbf{1 3}}$.

Rezygnując ze szczegółowych badań, a zwłaszcza ze żmudnych porównywań z wszystkimi spisami cudów z późniejszego okresu, wydaję poniżej tekst $\mathrm{w}$ zasadzie $\mathrm{w}$ takiej formie, w jakiej się zachował. Jedyne zmiany wprowadzam w układzie graficznym tekstu. Ponieważ jest on niekompletny (brak początkowych wyrazów każdego wiersza), a istniejących luk nie sposób bez reszty usunąć, podaję tekst w ten sposób, że

${ }_{13} \mathrm{Na}$ marginesie powyższych uwag warto jeszcze dodać następującą informację. W zaginionym rękopisie $\mathrm{nr} 3297$ Biblioteki Zakładu Narodowego im. Ossolińskich był słownik zwany Rosarius. $\mathrm{Na}$ f. $259-277$ wpisano Casus pulcri de vitandis erroribus consciencie. Doktorowie dekretów i teologii Uniwersytetu Krakowskiego: Stanisław ze Skarbimierza, Jakub z Zaborowa, Jan Elgot, Dersław z Borzynowa, Paweł z Zatora, Andrzej z Kokorzyna, Jan z Kęt, wypowiedzieli się w kwestiach spornych dotyczących sumienia. Występuje tu przypadek kobiety zasypanej przy kopaniu ziemi i uratowanej, która obiecała odbyć pielgrzymkę na Jasną Górę (,in mente votum vovit ad limina b. Virginis Czansthochoviam"), lecz mąż nie pozwalał jej dopełnić tego ślubu. Rozstrzygnięcie brzmiało, że biskup udzieli dyspenzy i zmieni ów ślub. - Por.: A. Brü ckner, Drobne zabytki języka polskiego. „Rozprawy Akademii Umiejętności, Wydział Filologiczny” 25 (1897) s. 277. 
każdy jego wiersz zaczyna się od swego właściwego początku czyli od miejsca obcięcia, zaznaczonego dwiema prostopadłymi kreskami. Nie liczne uzupełnienia wyrazowe zostały wprowadzone $\mathrm{w}$ miejscach nie budzących wątpliwości co do oczywistości takich koniektur. W przypisach podaję jedynie dla porównania redakcję poszczególnych cudów wymienionych w Historia pulchra Piotra Radzyńskiego. Chciałabym, aby miracula jasnogórskie z r. 1435 zostały włączone do całościowego opracowania tego przedmiotu, przygotowywanego przez s. Aleksandrę Witkowską, której przy okazji składam serdeczne słoła podzięki za informacje udzielone mi podczas opracowywania niniejszego artykułu.

\section{[MIRACULA CLAROMONTANA ANNO 1435 DESCRIPTA]}

$\|\left\langle\right.$ Anno Domini $\mathrm{MCCC}^{\circ}$ tricesi $\rangle \mathrm{mo}$ quinto indiccione tredecima pontificatus sanctissimi in Xpo patris et domini nostri domini Eugenii ${ }^{1}$ di $\langle$ vina $\rangle$

II ii, hoc est sabbato proximo in vigilia Sancti Spiritus et diebus tribus festivis eiusdem festi ho $\langle\mathrm{ra}\rangle$

\| 〈or >dinis fratrum hermitarum sancti Pauli primi heremite ordinis sub regula beati Augustini in mei

II presencia constitutus personaliter venerabilis vir frater Andreas ${ }^{2}$, prior provincialis fratrum heremi〈tarum $\rangle$

II suis confratribus sibi coventualiter ibidem demorantibus diocesis Cracouiensis requisivit

\|l en ad limina beate Marie semper Virginis illibate de partibus diversis utriusque sexus ibidem

I| masculus quam famella revelavit seu revelabant opressiones, infirmitates eorum sub iura 〈mento〉

li $\langle$ acci $\rangle$ pio hec super meam conscienciam quod ista omnia sunt et fuerunt vera, que coram te domine notarie

$\| \mathrm{k}^{\mathrm{a}}$ infirmabant ad oculos ambo per unum annum et maxime torquebantur et nisi vovimus

II firmum febrium per unum annum et sana facta est ad preces beate Mariae Virginis et sic deinceps omnis

\footnotetext{
a następuje przekreślone inf.

1 Eugeniusz IV, papież w latach 1431-1439, zm. 1447.

2 Andrzej przeor prowincjonalny paulinów występuje w r. 1436; zob. Fijałek, jw., s. 205 ( $\mathrm{nr} 109$ ).
} 
II per sex septimanas, quod nullus hominum dixit vitam, sanus factum est. Gregorius de Cze

\| $\langle$ d $\rangle$ e Cosslye ${ }^{3}$ corrosiones infinitas habuit in corpore suo per unum annum. Cristina de Pilsna 4

\| Chrapkouice ${ }^{5}$ fuit representatus per opidanos de Neymodling ${ }^{6}$ episcopo Wratislauiensi et fuit

II dolorem in pedibus fere per tres annos. Nikel de Rathiborz ${ }^{7}$ paciebatur dolorem in cor〈pore $\rangle$

II i secum ad limina apportavit, quem ego notarius in manibus propriis habui. Martinus de Szy

11 Iohannis Kwucza de Ilkusch ${ }^{8}$ vir suus predictus febricitabat per duos annos. Margare〈tha $\rangle$

|| 〈ia〉cuit in idropisi a festo sancti Laurencii et tres septimas post Pascha. Dorothea de Cruplin ${ }^{9}$

$\|$ virgo de $\langle\ldots\rangle$ non audivit per unum annum. Hannus de Dzetrzichouice ${ }^{10}$ fuit persagitatus

\| et sic iterum vovit et complevit. Et sanitatem recepit. Paulus de Rownya ${ }^{11}$ fassus est

I| $\left\langle\right.$ Math〉ias de Rathiborz ${ }^{12}$ paciebatur dolorem corporis per duos annos et puer suus non potuit

$\|$ os oculorum. Dochen de Domaracz ${ }^{13}$ febricitabat $\mathrm{X}$ septimanis. Mathias de ibidem

${ }^{3}$ Koźle, woj. opolskie, Cf. Risinius, f. D Iv: Ioannes vir quidam loco Coslin oriundus corrosiones diversas paciebatur, voto Mariae salvatus est.

4 Pilzno, woj. tarnowskie. Cf. R is inius, f. D Iv: Mulier civitate Pylsno oriumda demonio tempitabatur adeo, ut visu pnivaretur venliendo ad sacellum imaginis Mariae sanata est.

5 Krapkowice, woj. opolskie. Cf. Risinius, f. D IIr: Cracoviensis vir quidam Cramarczik accusaitus coram epilscopo Vraltislauiensi crimine falsitatis itaque vinctus et ergasistulo eterno deputaitus votum vovens Maniae liberatur.

- Niemodlin, woj. opolskie.

7 Racibónz, woj. katowickie. Cf. R is inius, f. D IIr: Nicolaus vir quidam civitate Rathiboria gravi dolore lapidis torquebatur itaque votum vovens adeo magnum per urinam egesisiit, ut nussi sillvestri essset iure camparandus.

8 Olkusz, woj. krakowskie. Cf. Risiniu s, f. D IIr: Ioannes Kuncza loco Ilkus oriundus biennio integro gravissima febri torquebatur votum vovens Mariae sanitati restitutus est.

9 Kruplin, woj. częstoochorwskie. Cf. Risinius, f. D IIr: Eodem oppido femina Dorothea tanta ydropisi laborabat, ut annum integrum superaret, voto sanata est. Alia item femina Cruplin loco oriunda morbo caduco laborans praesidio Mariae libenaltur. Vingo Anna loco Zamnowyecz oriunida biennio initegno sumda cum esset, vorto Mariae libenaltur.

10 Wietrizychorwice, woj. tarnorwskie. Cf. Risimius, f. D IIr: Ioannes Czeyczychowycza orliundus ab Hussitis sagitta acritter vulneraltus, voito Mariae sanartus est.

11 Miejscowość nie zlokalizowana.

12 Zob. przyp. 7.

13 Domaradz, woj. opolskie. Cf. Ris inius, f. D IIv: Agricola quidam rure Domaracz febricitans decem septimanis, voto Mariae liberatur. Eodem rure et alter integro anno febrem passus, pari modo voto Mariae liberatur. 
II III septimanis et non ambulavit. Katherina uxor Nicolai de Oppauia ${ }^{14}$ paciebatur

II tina dixerunt, quod puer ipsorum fuit crematus per totum et torquebatur gravissime ${ }^{15}$. Dorothea

|| Mathias de Larislawice ${ }^{16}$ prope castrum Ribnik submersus fuit in flumine Odra cadens

II aput eos per duos annos ${ }^{17}$. Duo Nicolai iuvenes de Wolwram ${ }^{18}$ iaucerunt in gravi 〈febre〉

|| bi incurvata per viginti septimanas. Petrus de Schynouice ${ }^{19}$ habuit dolorem in oculis

II nomine Martinum ${ }^{20}$, quem Husite receperant et mansit cum ipsis quatuor annos. Iacobus ${ }^{21}$

II est. Item alia vice idem Husite receperant sibi equum, quem solum habuit et post quatuor

II ipsis non potuit loqui per duas septimanas neque comedit neque bibit. Elizabeth de

II terra Rathiboriensi habuit dolorem in manibus quod non potuit ${ }^{\mathrm{b}}$ ipsis aliquod ma

|| mortua. Hedwigis Nicolai de Sulicouice ${ }^{22}$ in gravem infirmitatem posita non vidit

\| Dorothea mulier de Wartha ${ }^{23}$ paciebatur febres per unum annum. Anna mulier de

II. $\langle$ dolo $\rangle$ rem in toto corpore et in pedibus per medium annum nec potuit ambulare. Anna de Wyo

b następuje przekreslone loqui.

14 Opawa w północnych Morawach, dawniej należąca do Sląska. Cf. Risinius, f. D IIv: Katherina civitate Oppavia integro anno gravi febre torquebatur se vovens Mariae convaluit.

${ }^{15}$ Cf. Risinius, f. D IIv: Cuiusdam Petri Sathor oppido oriundi filius igne perustus acerbe torquebatur, voto Mariae sanatur.

${ }_{16}$ Miejscowość nie zlokalizowana. Cf. Risinius, f. D IIv: Mathias Piscator Latislawycze loco oriundus tempestate derepente exorta naufragium in Odera fluvio passus est. Itaque in profundum absorptus presidio Virginis ad ripam defertur.

17 Cf. Risinius, f. D IIv: Dorothea loco Swavulth gnatum unicum babens, qui per Hussitas vi raptus est, nunc illa vato Mariae vovens biennio elapso perditum nacta est.

18 Wolbrom, woj. katowickie. Cf. Risinius, f. D IIv: Duo nati civis Volbraniensis febre graviter affecti, voto Mariae sanantur.

19 Szonowice, woj. opolskie. Zob.: S. R o s p ond, Patronimiczne nazwy miejscowe na Slasku, Wrocław 1964, s. 92, 174.

${ }_{20} \mathrm{Cf}$. Risinius, f. D IIIr: Martinus loco Gostkowycze oriundus vi ab Hussitis raptus quadriennio integro cum eis commoratus se vovens Mariae liberatur. ${ }^{21} \mathrm{Cf}$. R is in i u s, f. D IIIr: Post hunc pari modo Iacobus loco Szyeniskowicze oriundus erat captivatus votum vovens Mariae liberatur.

22 Sułkowice, woj. krakowskie.

${ }^{23}$ może Bardo, woj. wałbrzyskie. 
$\|$ 〈inf)irmabatur gravi infirmitate cum puero ipsius ad $\mathrm{V}^{\mathrm{m}}$ annum ita quod non potuit loqui

|| Nicolaus de Pylsna ${ }^{24}$ iacuit per septem septimanas in gravi $^{c}$ infirmitate ita quod nullus

|| Mathiàs fuerat incaptivatus per Husitas, ligatus et suspensus et promisit se visitare solum

\| $\langle$ st $\rangle$ atim revixit, qui fuit mortuus. Nicolaus de Pylsna 25 datus fuit ad graves angustias

\| quod potuit mori. Nicolaus filius eiusdem iacuit in gravi infirmitate per medium annum. Mar〈tinus〉

\|l de Namislouia ${ }^{26}$ infirmabatur gravissime ita quod iam per tres non loquebatur dies una cum

\|l vertebat ad occiput et econtra. Michael de ibidem ex casu de infortunö cecidit de

II na de Cracouia paciebatur infirmitatem gravem ita, quod lumen da'batur suis manibus

|| louia fuit detentus per Husitam appellatum Puklicz. Hannus de Mrithow a Glogovia ${ }^{27}$

$\|$ it in valida infirmitate ita ut lumen sibi iam porrigebatur in agone et intuens nudatum [?]

|| promissa sana surrexit. Dorothea uxor Cunradi de Pylsna ${ }^{28}$ paciebatur dolorem

$\|$ in spiritum [?] per tres septimanas. Katherina uxor Iohannis de Szary ${ }^{29}$ iacuit infirmitate

\| quatour annos. Martinus de Grziszowniky ${ }^{30} \|$

DIE WUNDER DER MUTTER GOTTES MARIA AUS CZĘSTOCHOWA REGISTRIERT IM JAHRE 1435

Zusammenfassung

In der Handschrift 2322 aus dem fünfzehnten Jahrhundert der Jagiellonischen Bibliothek in Krakau hat die Verfasserin ein Fragment der lateinischen Notariatsurkunde gefunden, die die kurzen Beschreibungen der Wunder, auf Fürbitte von Schwarzer Madonna hin getan, zusammenstellt. Der Text ist auf dem unteren Pergamentschutzblatt (postfolium) geschrieben, das leider von einem Buchbinder

\footnotetext{
c następuje przekreślone ita.

24 Zob. przyp. 4.

25 Zob. przyp. 4.

${ }^{26}$ Namysłów, woj. opolskie.

27 Głogów, woj. legnickie.

28 Zob. przyp. 4.

${ }^{29}$ Żory, woj. katowickie.

30 Krzyżowniki, woj. kaliskie.
} 
so zugeschnitten worden war, daß jetzt die Anfänge der Zeilen und der Schluß des Textes fehlen. Daher sind bloß 46 Zeilen erhalten.

Die Urkunde enthält die Bekunden der in Częstochowa eingetroffenen Pilger, die sie vor Andreas, dem Prior des Klosters, an den Tagen von 4. bis 7. Juni 1435 ausgesagt hatten. Es gibt hierher ungefähr 50 Aussagen der wunderbarerweise Gesundgemachten oder aus der Todesnot Geretteten, deren überwältigende Mehrheit nach Częstochowa aus Oppelnkreis, doch aber auch aus Kleinpolen gekommen war, um dort das Gelübde der Danksagung Mutter Gottes entgegen zu erfühlen und Zeugnis des wunderbaren Ereignisses abzulegen. Die hiermit herausgegebene Urkunde ist die älteste dieser Art, die den frühen Kultus der dortigen Schwarzen Madonna, nämlich schon 50 Jahren nach der Gründung des Paulinerklosters auf Jasna Góra in Częstochowa vom Herzog Ladislaus von Oppeln (1383) bezeugt. Damit ist auch eine Nachricht von Johannes Długosz bestätigt, der in seiner Historia Polonica (vollendet 1480) anführt, daß man noch vor 1430 nach Częstochowa aus dem ganzen Königreich Polens, und auch aus Schlesien, Preußen und Ungarn wallfuhr, wegen der Wunder, die dort von der Mutter Gottes getan wurden 